\title{
EMPLEO Y JUBILACIÓN: ¿RECONSTRUCCIÓN O CAMBIO DE PARADIGMA?
}

Employment and retirement: reconstruction or paradigm shift?

\author{
Arántzazu Vicente Palacio*
}

Catedrática de Derecho del Trabajo y de la Seguridad Social. Universidad Jaume I-Castellón

\section{RESUMEN}

¿Se halla en el mercado (financiero) la solución a los problemas de los sistemas de Seguridad Social europeos surgidos tras la Segunda Guerra Mundial? Basados en la técnica financiera del reparto — traducción de los valores de solidaridad profesional e intergeneracional — parecen incapaces de asegurar su sostenibilidad futura a medio y largo plazo debido al incremento de la esperanza de vida, la reducción de las tasas de natalidad y los altos niveles de desempleo. Este diagnóstico no es nuevo pues las dificultades económicas han acompañado desde sus orígenes a los sistemas de seguridad social (DURAND, 1953; VENTURI, 1954). La novedad radica en las soluciones propuestas: el recurso en mayor o menor medida al mercado financiero y en el consenso social, parlamentario y ciudadano que suscita esta solución. Este consenso no es casual: desde hace ańos, el poder financiero mundial ha desembarcado en buena parte de los medios de comunicación con la finalidad de crear una "única» solución a la crisis de los modelos de reparto: su capitalización en el mercado financiero.

Este estudio resume las características tradicionales del sistema español de seguridad social (en general, del modelo europeo), las distintas reformas normativas operadas en los últimos ańos y el grado penetración de importantes grupos financieros en los medios de comunicación —acrecentado con la última crisis financiera-, para poner de manifiesto que nos encontramos ante un cambio de paradigma para la protección de la jubilación y que en este cambio sólo hay un vencedor: el poder financiero mundial.

Palabras clave: Seguridad social; Medios de comunicación; capitalización; poder financiero; fondos de pensiones; fondos de inversión; reparto; jubilación; vejez.

\section{ABSTRACT}

Is the (financial) market the solution to the problems of the European Social Security systems that emerged after the Second World War? Based on a pay-as-you-go basis —-the technical translation of the values of professional and intergenerational solidarity - they seem incapable of ensuring its future sustainability in the mid and long terms due to increased life expectancy, lower birth rates and high unemployment levels. This diagnosis is not new: economic difficulties have accompanied Social Security from its origins (DURAND, VENTURI). The novelty lies in the proposed solutions: an appeal, to a greater or lesser extent, to the financial market, and in the social, parliamentary and citizen consensus that gives rise to this solution. This consensus is not coincidental: for years, global financial power has landed in most mass media to create a "unique» solution for the crisis of pay-as-you-go basis models its capitalization in the financial market.

This study summarises the traditional characteristics of the Spanish Social Security System (generally from the European model), the different regulatory reforms operated in recent years and the degree of penetration of important financial groups in mass media — which increased with the last financial crisis - to show that we are facing a paradigm shift to protect retirement, and that there is only one winner in this change: global financial power.

Keywords: Social Security; Mass Media; Capitalisation; Financial power; Investment funds; pay-as-you-go; Old-age pension.

* Correspondencia a: Arántzazu Vicente Palacio. Avinguda de Vicent Sos Baynat s/n. 12071 Castellón de la Plana - vicente@uji. es - https://orcid.org/0000-0002-6559-4386

Cómo citar: Vicente Palacio, Arántzazu. (2018). «Empleo y jubilación: ¿reconstrucción o cambio de paradigma?»; Lan Harremanak, 40, 49-66. (https://doi.org/10.1387/lan-harremanak.20328).

Recibido: 2 noviembre, 2018; aceptado: 2 diciembre, 2018

ISSN 1575-7048 - elSSN 2444-5819 / (c) 2018 UPV/EHU

(c) Esta obra está bajo una licencia

Creative Commons Atribución 4.0 Internacional 


\title{
SUMARIO
}

1. El modelo europeo de seguridad social: desmercantilización (o publificación) de las necesidad sociales.-2. Factores de riesgo y reformas: desde la inicial reducción de la suficiencia de las pensiones públicas al cambio de paradigma de protección.-3. La unicidad de las soluciones: ¡se trata de un cambio de paradigma económicamente neutral?-4. Un epílogo y tres conclusiones.-5. Bibliografía.

\begin{abstract}
«Si se crea una percepción lo suficientemente fuerte de que el Estado del Bienestar se encuentra agonizando, se logra que resulte más fácil podar otras partes sin que nadie pregunte adónde fueron a parar.» (Nicholas Timmins, The Five Giants. A biography of the Welfare State, 1995)
\end{abstract}

\section{El modelo europeo de seguridad social: desmercantilización (o publificación) de las necesidad sociales}

La opción histórica de los reformadores sociales europeos a favor de los sistemas de seguridad social de tipo contributivo-profesional tuvo como lógico efecto la configuración de un binomio inseparable entre el trabajo y la seguridad social. Mas concretamente, fue el recurso a la técnica aseguradora la determinante de esta relación. Fracasado el sistema de libertad subsidiada ensayado en un primer momento a través del Instituto Nacional de Previsión (1908), la siguiente etapa en la construcción del sistema de seguros sociales fue la obligatoriedad en el aseguramiento de algunos de los riesgos derivados de la prestación de servicios por cuenta ajena en la nueva sociedad industrial. Esta conexión revolución industrial-alienación del trabajo/trabajador es clave en la gestación del sistema de seguros sociales y también en la delimitación de la población protegida por estos seguros sociales. El escaso papel y capacidad económica del Estado, marcado por el liberalismo político y económico de la época, la insuficiencia de recursos de la clase obrera y la estrecha vinculación de los impulsores de los seguros sociales con compañías aseguradoras determinó, por un lado, la necesidad de implicar a los patronos de la nueva clase trabajadora en la financiación de la protección social, junto al beneficiario y al Estado; y, por otro, el recurso a la técnica aseguradora como mecanismo para la dispersión de los riesgos recién socializados. De hecho, sólo los obreros de menor capacidad económica estaban comprendidos en su campo de aplicación, de forma que posiblemente 
pueda afirmarse que el adjetivo «social» de los seguros sociales iniciales tenía un significado bien diferente del actual (Heyde, 1931; Molleda, 1988; AAVV, 2000; AAVV, 200).

La realizacion de actividad laboral no sólo condicionaba la adscripción o pertenencia del ciudadano (que sólo era relevante en tanto trabajador) a los seguros sociales sino que también desplegaba otros muchos efectos, tales como la necesidad de que el trabajador mantuviera viva esa relación laboral en el momento del hecho causante (alta o situación asimilada), o su contribución económica al sistema (exigencia de periodo de carencia para prestaciones derivadas de enfermedad común), efectos que, en general, y con algunas salvedades o matizaciones, perduran en la actualidad. Las prestaciones económicas del sistema de seguros sociales se configuraron como rentas sustitutivas de las rentas salariales perdidas a resultas de la actualización de los riesgos protegidos y sólo muchos años después se ha diluido — que no roto — esta conexión al permitirse el acceso a algunas prestaciones económicas desde la situación de no alta o asimilada ${ }^{1}$. El sistema de responsabilidad en materia de prestaciones por incumplimiento de las obligaciones empresariales es un claro ejemplo que todavía perdura y, en materia de jubilación, es especialmente significativo (AESSS, 2012).

No fue casualidad que el primer seguro social fuera el Retiro Obrero (1919) - obligatorio a partir de 1921 - y que fuera un sistema financiero de capitalización. En su función de instrumento para la consecución de la "paz social» tenía un indudable papel apaciguador, con la ventaja de no implicar a corto/medio plazo el pago de prestaciones. Incluso yendo mas lejos, tampoco a largo plazo suponía la asunción de grandes riesgos económicos al fijarse como edad del retiro los 65 ańos, cuando la media de la esperanza de vida se situaba lustros por debajo de dicha edad. Habría que esperar en algunos casos muchos años para que los seguros obligatorios cubrieran riesgos sociales determinantes de protección más inmediata: maternidad (1929); enfermedad (1942); invalidez (1947); muerte y supervivencia (1955) y desempleo (1961).

El actual sistema español de seguridad social se ha caracterizado desde su nacimiento (1967), por los siguientes rasgos:

a) La socialización del riesgo de la pérdida de rentas salariales a través de la técnica aseguradora. Inicialmente los riesgos protegidos fueron los di-

${ }^{1}$ La Ley 26/1985, de 31 de julio, permitió el acceso a la pensión de incapacidad permanente absoluta y jubilación desde la situación de no alta o asimilada al alta, aunque exigiendo un periodo de cotización previa superior al supuesto clásico de acceso desde la situación de alta o asimilación al alta. La Ley 40/2007, de 4 de diciembre, permitió también el acceso desde la situación de no alta o asimilada a las pensiones de viudedad y orfandad. Esta última Ley también suprimió el requisito del periodo de carencia para el acceso a la pensión de orfandad cuando el trabajador causante fallece estando en alta o situación asimilada al alta. 
rectamente vinculados a la actividad laboral y sólo mas recientemente se han socializado otros riesgos (paternidad; cuidado de menores enfermos de cáncer u otra enfermedad grave).

b) La convivencia, muy desigual en su intensidad protectora, de dos niveles de protección: el contributivo y el no contributivo. Desde la aprobación de este último (Ley 26/1990, de 20 de diciembre) las prestaciones y su ámbito de cobertura se mantienen prácticamente idénticos.

c) La separación de las fuentes de financiación entre ambos niveles de protección: la financiación profesional a través de cuotas en el nivel contributivo y la financiación fiscal para el nivel no contributivo. Desde el Pacto de Toledo (1995) y su concreción legal (1997), todas las prestaciones que el TRLGSS configura como no contributivas se financian vía fiscal, incluyendo los complementos por mínimos.

d) La opción por un sistema financiero de reparto como manifestación de la solidaridad «intergeneracional», pues lo cotizado por la totalidad de los trabajadores se destina a sufragar las pensiones de quienes son, en el mismo espacio temporal, beneficiarios de pensiones. Por definición, el sistema de reparto excluye la acumulación de capital y por consiguiente, su movilización en el mercado de capitales, con la salvedad de los excedentes o superávits que puedan producirse en cada momento, que pasan a integrar eventuales fondos de reserva.

e) La configuración de las prestaciones económicas del nivel contributivo como rentas sustitutivas del salario de tal forma que, en lo que se refiere a la jubilación y desaparecida con carácter general la jubilación forzosa, el hecho causante exige la concurrencia (simultánea o no) de dos circunstancias: el cumplimiento de la edad establecida en cada caso y el cese en el trabajo.

f) Derivado de lo anterior, la tradicional incompatibilidad de la pensión de la jubilación con el trabajo, por cuenta propia o ajena.

\section{Factores de riesgo y reformas: desde la inicial reducción de la suficiencia de las pensiones públicas al cambio de paradigma de protección}

Dos virus parecen afectar la salud de los sistemas de seguridad social: el envejecimiento de la población y las altas tasas de desempleo. La dependencia de los sistemas de reparto de ambas variables — que serán críticas con la llegada de la generación del baby boom a la edad de jubilación — ha llevado al legislador a adoptar medidas para asegurar la sostenibilidad del sistema. Resulta interesante poner de manifiesto que el discurso político resulta idéntico en todos los países europeos, con independencia de su esperanza de vida y de su nivel de desempleo 
e incluso de las diferencias demográficas o de cualquier otra singularidad nacional (población; producto interior bruto; deuda pública, costes sociales, carga impositiva, etc.). Incluso el lenguaje al que recurre el discurso político ha sufrido una interesante mutación: la sostenibilidad ya no es económica sino financiera; mientras lo económico remite a la administración eficaz para satisfacer las necesidades humanas materiales con bienes escasos, lo financiero alude a cuestiones bancarias o bursátiles. Un sistema de reparto no precisa de sostenibilidad financiera sino de una adecuada y eficaz administración de unos recursos económicos que siempre son escasos.

El legislador lleva años adoptando distintas medidas para gestionar los recursos limitados del sistema de seguridad social. En el caso español, son reformas adoptadas desde el consenso parlamentario y social en un intento de sustraer del conflicto electoral y social una institución que goza en nuestro país de un amplio respaldo. Este consenso admite también otra lectura menos complaciente, como se expondrá con posterioridad. Sin ánimo exhaustivo, las medidas adoptadas para asegurar la sostenibilidad del sistema de seguridad social y específicamente, de la que constituye su pilar fundamental han sido las siguientes (Vicente-Palacio, 2015):

a) Se ha operado un progresivo endurecimiento de los requisitos de acceso a la pensión de jubilación. Sin ninguna referencia a eventuales problemas de sostenibilidad ${ }^{2}$ se incrementó el periodo de carencia exigible pasando de diez a quince años (1985). Además, la clásica doctrina jurisprudencial de los días-cuota — que facilitaba el cumplimento de este requisito - fue atajada por el legislador años más tarde $(2007)^{3}$ eliminando expresamente su aplicación a las pensiones de jubilación y donde la sostenibilidad financiera aparece ya en dos ocasiones como razón que impele la reforma, en una difícil convivencia con el reforzamiento de los

2 Ley 26/1985, de 31 de julio: «Desde los años iniciales de la crisis económica ha sido constante y generalizada la opinión de que la Seguridad Social está necesitada de profundas reformas, punto sobre el que, puede afirmarse, existe hoy una práctica unanimidad por parte de las fuerzas sociales y politicas $m A ́ s$ representativas. Pero el ya muy largo proceso indicado ha hecho que los desequilibrios producidos en el sistema estén actuando negativamente sobre la economía y el empleo y poniendo en peligro el propio éxito de la reforma que se está abordando, en orden a garantizar su viabilidad y particularmente el mantenimiento del nivel y necesaria actualización de las pensiones. Las medidas que se aprueban en la presente Ley se inscriben en esa primera fase de rectificación de los defectos y desviaciones más notorias y urgentes, $y$ persiguen los siguientes objetivos: reforzamiento del carácter profesional, contributivo y proporcional de las pensiones de jubilación e invalidez; correlativa mejora de la protección no contributiva; mejora de la eficacia protectora por la reordenación de recursos, y racionalización de la estructura del Sistema».

3 Ley 40/2007, de 4 de diciembre: "(...) todo ello en el contexto de las exigencias que se derivan de la situación sociodemográfica, de la que resaltan circunstancias tales como el envejecimiento de la población, la incorporación creciente de las mujeres al mercado de trabajo y el fenómeno de la inmigración, asi como de los criterios armonizadores hacia los que se apunta en el ámbito de la Unión Europea, con el objetivo de garantizar la sostenibilidad financiera del sistema de pensiones» 
principios de solidaridad y de contributividad también invocados por la reforma.

Especial referencia merecen las consecuencias que se atribuyen al trabajo a tiempo parcial para el cómputo del periodo de carencia; tras varias idas y venidas en las que la intervención de los Tribunales ha jugado un papel fundamental, en la actualidad el coeficiente global de parcialidad constituye la materialización de la estricta aplicación del principio de proporcionalidad en el caso del trabajo a tiempo parcial de tipo horizontal, pero no así en el vertical que a estos efectos mantiene el tratamiento discriminatorio que el TJUE ha considerado en relación con la prestación de desempleo (y que ha sido corregido reglamentariamente en relación a esta por el RD 950/2018, de 28 de julio).

b) Los parámetros para el cálculo de la cuantía de la pensión ha sido otro de los aspectos sobre los que el legislador ha vuelto con insistencia, ampliando en los últimos ańos el espectro de las medidas adoptadas. Todas ellas convergen en la misma finalidad: la reducción del gasto, no mediante una mejor gestión de los recursos sino mediante la reducción de la cuantía de las prestaciones.

El incremento del periodo computable para el cálculo de la pensión pasó de cinco (1974) a ocho años (1985), a quince años (1997) y a veinticinco (2013) que será de total aplicación a partir de 1-1-2022. En definitiva, en cuarenta y siete años se ha quintuplicado el periodo de referencia para el cálculo de la base reguladora.

La reducción de la cuantía de la prestación que se deriva de esta ampliación se agrava como consecuencia de otras reformas. La elevación del número de años de cotización (37 años) exigidos para cobrar el 100\% de la pensión y especialmente, la reducción del sistema de integración de lagunas, cuya probabilidad aumenta con la ampliación del periodo de referencia de la base reguladora: si con anterioridad estaba asegurada su integración con la totalidad de la base mínima de cotización para mayores de 18 años, esta garantía fue limitada (2011) a cuarenta y ocho mensualidades limitándose al $50 \%$ de dicha base la integración de las restantes mensualidades. En ambos casos y para los trabajadores a tiempo parcial, la base mínima a tener en consideración es la correspondiente al número de horas contratadas en último término lo que se aleja completamente de las reglas de contributividad y proporcionalidad reiteradamente invocadas.

La limitación de los complementos por mínimos a la cuantía anual de las pensiones no contributivas resulta también en la reducción de la protección pública. La separación de las fuentes de financiación entre ambos niveles del sistema y la que entonces (1997) parecía una medida razonable de remitir a la financiación fiscal los complementos por mínimos como manifestación de solidaridad nacional —ya no profesional, como antaño - y dedicar los excedentes 
del nivel contributivo a la constitución de reservas se ha tornado en una medida reaccionaria. Su finalidad no es evitar el trasvase de fondos desde el nivel contributivo al nivel no contributivo sino lo contrario: bajo la apariencia de un tratamiento supuestamente igualitario de la protección financiada fiscalmente se reduce el ámbito de la suficiencia en el nivel contributivo.

Mención aparte merece la reforma del sistema de revalorización y la introducción del factor de sostenibilidad. Las variables tomadas en consideración por el nuevo Índice de Revalorización (2011) —ingresos y gastos del sistema de pensiones, el número de pensionistas y la evolución de la pensión media- están vinculadas exclusivamente a la sostenibilidad financiera del sistema y no a la suficiencia de la pensiones o al mantenimiento de su poder adquisitivo. Dado que todas estas variables tienen previsto en los próximos ańos una evolución negativa, la reforma se traduce en la aplicación durante un largo periodo de tiempo de la irrisoria garantía mínima de un índice de 0,25\% IPC. El vago acuerdo adoptado en la Comisión Parlamentaria del Pacto de Toledo permite diversas interpretaciones y habrá que esperar a ver qué ocurre con los Presupuestos Generales del Estado para 2019.

Finalmente, el Factor de Sostenibilidad (2013) actúa directamente sobre la determinación de la cuantía inicial de la pensión de jubilación operando nuevamente con una variable desvinculada de la contributividad y proporcionalidad: la esperanza de vida, en lo que constituye una cínica manipulación del concepto de «solidaridad intergeneracional», de resonancias positivas en el ámbito de la justicia natural. Con la finalidad de «ajustar la pensión inicial de manera que el importe total que perciba a lo largo de toda su vida un pensionista que acceda al sistema de pensiones dentro de un cierto número de años y que previsiblemente tendrá mayor esperanza de vida sea equivalente al que percibe el que se jubile en un momento anterior» el sistema se ha transformado desde un modelo de aportación y prestación definidas a un modelo de prestación indeterminada (Tortuero Plaza, 2014). Aparece así otra de las características de la nueva modernidad: la aceptación del papel residual del Estado en la gestión del riesgo cuyo papel debe limitarse a fomentar la protección mediante mecanismos financieros capitalistas. El incremento de esperanza y calidad de vida es un problema, más que una conquista social y este nuevo riesgo constituye un nuevo nicho de negocio (sociedad reflexiva) para un nuevo capitalismo liberado y cada vez más poderoso.

Especial referencia merecen la sucesivas reformas del régimen de compatibilidad de la pensión de jubilación con el trabajo. En la evolución de la protección de la vejez, el legislador ha recurrido a distintas denominaciones y resulta difícil resolver si estos cambios obedecen simplemente a la voluntad de diferenciarse de sus predecesores o si responden a un cambio del riesgo o situación protegida. Algún autor ha señalado que el Retiro Obrero no establecía en ningún momento la incompatibilidad de la pensión con el trabajo, pero es que posiblemente era 
innecesaria una prohibición legal expresa, dado que si pocos de los trabajadores comprendidos en su ámbito de aplicación llegaban a cumplir 65 ańos, muchos menos lo harían en condiciones de continuar desarrollando su actividad laboral. Y es que la relación que el legislador establezca entre trabajo y el derecho a la percepción de la pensión constituye un claro indicio de cual es la situación de necesidad protegida económicamente por la actual pensión de «jubilación».

Nuestro actual sistema de Seguridad Social estableció explícitamente la incompatibilidad entre el trabajo y el pensión de jubilación y, en general, con todas las pensiones, y también la de incapacidad permanente ${ }^{4}$. Lógicamente hay diferencias entre ambas pero la situación de necesidad protegida es (era) idéntica en ambos casos: la pérdida de los ingresos derivados del trabajo por el cese en el trabajo, bien a causa de la edad bien por la incapacidad para continuar desarrollando la actividad laboral. Las prestaciones económicas se configuraban pues, como rentas sustitutivas de las rentas salariales, con alguna excepción residual ${ }^{5}$. La realización de trabajo retribuido por el pensionista de jubilación determinaba la suspensión de la pensión, sin que las nuevas cotizaciones pudieran tener efecto sobre la cuantía de la pensión cuando al finalizar su prestación laboral, se reanudara su abono. Es en el marco de las (iniciales) políticas blandas de retraso en el acceso a la pensión de jubilación y de fomento de empleo (2002) cuando se admite, por primera vez, la compatibilidad de la pensión de jubilación con el trabajo a tiempo parcial, reconociendo a las nuevas cotizaciones efectos sobre la cuantía de la pensión, al igual que en los supuestos de jubilación flexible, también articulada sobre el trabajo a tiempo parcial. Dado que la elevación general de la edad mínima de acceso a la pensión de jubilación parecía una medida imposible de adoptar en el marco del consenso social y parlamentario, el abono de una pensión parcial durante un cierto tiempo parecía una solución preferible al abono de su cuantía íntegra. Los escasos incentivos articulados para dotar de

\footnotetext{
${ }^{4}$ Situación particular es la pensión de viudedad, cuya caracterización se omite deliberadamente. Por lo que respecta al permisivo régimen de compatibilidad de la pensión de incapacidad permanente en sus grados de absoluta y gran invalidez con el trabajo es fruto de la interpretación jurisprudencial (2002 y siguientes) de un precepto cuyo tenor literal no ha cambiado desde 1974 (salvo en el establecimiento reciente de la incompatibilidad cuando el trabajador cumpla la edad de acceso a la jubilación). Esta interpretación ha alcanzado incluso reconocer el derecho a tomar en consideración las nuevas cotizaciones realizadas durante el periodo de suspensión de incapacidad permanente por la realización de actividad laboral para el cálculo de la base reguladora de la pensión de incapacidad permanente que se reanuda con posterioridad [STS de 25-4-2018 (núm. rec. 2322/2016)]

5 Incapacidad Permanente Parcial; Lesiones Permanentes no Invalidantes (en caso de contingencias profesionales) e Indemnizaciones a tanto alzado en caso de fallecimiento por contingencias profesionales. Igualmente es preciso un replanteamiento de la cobertura de la viudedad. Las opciones son múltiples, pero es preciso recuperar la dependencia económica como situación de necesidad real protegida, y sin perjuicio de establecer medidas compensatorias de carácter temporal para permitir al supérstite ajustar su economía a la nueva situación familiar. El ahorro obtenido debería servir para mejorar la protección de la orfandad y de la propia viudedad cuando efectivamente exista situación de necesidad.
} 
atractivo a estas medidas, unido a la sospecha de un uso torticero, entre otras razones, motivaron sucesivas reformas normativas que han ido endureciendo progresivamente los requisitos.

El vigente régimen — supuestamente extraordinario- de compatibilidad de la pensión de jubilación con el trabajo es indicativo de que está operándose una sutil transformación de la situación de necesidad protegida, que ya no es la pérdida de los ingresos derivados del cese en el trabajo a consecuencia de la imposibilidad "presunta" de trabajar por razón de edad (lo que se verifica mediante la inactividad laboral), sino el mero cumplimiento de la edad en la que se fija el umbral de vejez. La pensión de jubilación aparece como la recuperación periódica de las cuotas abonadas (ahorradas), en la más pura configuración de un seguro de rentas de vejez, incluso si se mantiene el sistema financiero de reparto (cuentas nocionales). La técnica del seguro, que nunca ha desaparecido totalmente de nuestro sistema de seguridad social se alza con el protagonismo al convertir el riesgo asegurado (vejez) en la situación protegida (vejez).

En el régimen ordinario (art. 213 TRLGSS) se permite la compatibilidad de la pensión de jubilación con el trabajo a tiempo parcial, reduciendo en tal caso la cuantía de la pensión en el porcentaje de jornada que el trabajador lleve a cabo. Pero esta compatibilidad se flexibiliza notablemente cuando el trabajo se lleva a cabo por cuenta propia, pues en tal caso se permite percibir el $100 \%$ de la pensión de jubilación siempre que los ingresos percibidos por este trabajo no superen el $100 \%$ del salario mínimo interprofesional. Dada la dificultad de control de los ingresos de los trabajadores autónomos resulta evidente que esta medida supone la apertura total a la compatibilidad de la pensión de jubilación con el trabajo por cuenta propia, sin que además el sistema obtenga un «retorno de solidaridad" pues dicho trabajo está exento de cotizar (Ballester Pastor, 2018). De momento, la reducción del número de desempleados justifica la exclusión de la compatibilidad total de la pensión de jubilación con el trabajo por cuenta ajena con carácter general aunque no así en el régimen extraordinario. Efectivamente, otro tipo de razones ajenas a la política de empleo inspiran la regulación de la compatibilidad prevista en el art. 214 TRLGSS. Este precepto permite la compatibilidad de la pensión de jubilación con el trabajo por cuenta propia o por cuenta ajena y ya sea a tiempo completo o parcial, siempre que el trabajador haya accedido a la pensión de jubilación a partir de la edad mínima establecida, exigiéndose también que el porcentaje aplicable a la base reguladora para la determinación de la pensión sea del $100 \%$. La cuantía de la pensión se reduce al $50 \%$ con carácter general, porcentaje que es del $100 \%$ si la actividad es por cuenta propia y se acredita tener contratado al menos, un trabajador por cuenta ajena.

Dejando ahora aparte las discrepancias en relación a la aplicación de esta última compatibilidad por el Instituto Nacional de la Seguridad Social, la progre- 
siva aceptación de la compatibilidad de la pensión de jubilación con el trabajo abunda en el cambio de situación protegida por la pensión de vejez. La edad no implica una imposibilidad física para desarrollar una actividad profesional sino que el cumplimiento de una determinada edad permite recuperar las aportaciones realizadas a un "seguro" de vejez aunque no exista una efectiva (y de momento, total) pérdida de los ingresos proporcionados por el trabajo. Indudablemente, la flexibilización del régimen de compatibilidad también guarda conexión con la minoración de la tasa de sustitución de la pensión de jubilación resultante de las reformas operadas en los últimos años: el legislador está eliminando los obstáculos para permitir que el pensionista pueda complementar su pensión con ingresos derivados del trabajo amparándose en una manipulación del concepto de "envejecimiento activo», pues si bien es cierto que este concepto en sus primeros años atendió en alguna medida a la dimensión laboral, lo cierto es que la definición manejada por la OMS se aleja mucho en lo que a la seguridad y cuidados necesarios de la vejez se refiere a las consecuencias que cabe esperar de las reformas sobre la protección de la vejez.

\section{La unicidad de las soluciones: ¿se trata de un cambio de paradigma económicamente neutral?}

Una de las características de la "sociedad del riesgo» que tan tempranamente supo predecir la sociología (BECK, 1986) fue el dominio absoluto de los medios informativos por los grupos de presión ligados al capitalismo mas salvaje o, en su caso, a los poderes públicos, con la finalidad de generar un pensamiento social uniforme. La tergiversación de la información y la manipulación de las emociones - especialmente el miedo- durante un periodo continuo de tiempo erosionan la racionalidad, llevando a los individuos y a la sociedad al convencimiento del carácter unidireccional de unas soluciones que no son, ni social ni económicamente, neutrales.

La financiación es el escollo principal para cualquier sistema de seguridad social puesto que los recursos económicos son siempre limitados. Ya era así en 1919 (Retiro Obrero) y continúa siéndolo en la actualidad, tanto para los sistemas de reparto como para los sistemas de capitalización. Tanto es así que los términos seguridad social y crisis forman desde el nacimiento de aquélla un binomio inseparable. Los impulsores de los seguros sociales en toda Europa (Durand, 1953; Venturi, 1954) dedicaron mucho empeño a buscar soluciones adecuadas, que fueron sustituyendo y ajustando a las distintas situaciones sociales y económicas hasta llegar en buena parte de los países europeos a adoptar el sistema contributivo-profesional, financiado por cuotas y basado en la solidaridad profesional, complementado por un sistema no contributivo y universal, fundado en la solidaridad nacional. El fracaso de la capitalización en los primeros seguros ensayados condujo 
a la adopción de un sistema financiero de reparto (1931), aun con sus limitaciones, y los sistemas de Seguridad Social se convirtieron en un instrumento de solidaridad entre trabajadores y también intergeneracional. La evolución negativa de las variables demográficas de las que son tan dependientes los sistemas de reparto son conocidas desde hace décadas y ello no ha obstado para que los países europeos que implementaron medidas de fomento de la natalidad y cuyos niveles de desempleo son reducidos también hayan acometido reformas sistémicas, reformas que permanecerán cuando los babyboomers hayan desaparecido.

Todas estas reformas se han caracterizado, en general, por la introducción paulatina de medidas de capitalización, también en el ámbito de la protección pública, en mayor o menor medida (AESSS, 2013). Hasta fechas recientes, el debate sobre la capitalización estaba limitado al nivel complementario, especialmente al alcance del fomento público de los complementos privados de la pensión pública pero sin presentarse todavía como alternativa del sistema público. Las reformas emprendidas en los últimos años por algunos países europeos - fomentadas desde las propias instituciones comunitarias en el marco del Método Abierto de Coordinación (art. 160 Tratado) (Cairos Barreto, 2015) — tienen un alcance muy diferente: la capitalización alcanza también al nivel obligatorio y, específicamente al nivel contributivo-profesional, capitalización en la que, además, el ámbito público cede su tradicional ámbito de socialización a favor de la iniciativa privada. Si el sistema de protección social supuso la desmercantilización de algunas necesidades individuales por la vía de su socialización, la llamada a la capitalización privada en el ámbito de la protección del sistema público obligatorio constituye el completo abandono del tradicional principio de solidaridad profesional, en lo que constituye una reformulación del contrato social que ha regido el modelo social europeo durante los últimos cien años (Sánchez-Rodas, 2018).

Según el Barómetro del Centro de Investigaciones Sociológicas (CIS), el pasado mes de marzo 2018 la preocupación por las pensiones era uno de los tres principales problemas para el $15,5 \%$ de los españoles: duplicó la tasa del mes anterior y se alcanzó el máximo histórico ${ }^{6}$ ¿Qué es lo que ha ocurrido para que haya arraigado tan fuertemente en los individuos y en la sociedad el convencimiento de que el sistema actual es insostenible y de que se trata de una situación irreversible que demanda un cambio radical de modelo?

Sin negar la realidad incuestionable del problema de financiación en un modelo tan dependiente de dos factores cuya evolución futura es claramente negativa, el cambio de mentalidad social debe mucho al progresivo control de las distintas instancias de poder por el capitalismo financiero. Incluso el lenguaje ha ido cambiando sutilmente. La viabilidad o sostenibilidad económica se ha trans-

6 Vid. evolución en http://www.cis.es/cis/export/sites/default/-Archivos/Indicadores/ documentos_html/TresProblemas.html 
formado en sostenibilidad financiera ${ }^{7}$; las normas jurídicas adoptan una finalidad adoctrinadora ${ }^{8}$; organizaciones sindicales y los partidos políticos alejados de posiciones liberales suscriben pactos parlamentarios y acuerdos sociales sancionando la corrección política de las nuevas recetas (unidireccionales) y aceptan el nuevo papel residual del Estado en la gestión del riesgo social ${ }^{9}$. Y todo esto alentado por unos medios de comunicación que, a resultas de la crisis económicafinanciera, han pasado a estar bajo el control de fondos capitalistas, únicos beneficarios del trasvase de capital al mercado financiero que implica el cambio de modelo de protección social.

En la actualidad (2018) el Grupo Prisa cuenta entre sus principales accionistas con importantes fondos capitalistas: Amber Capital; Adar Capital; HSBC; Banco Santander ${ }^{10}$. Mediaset España está en manos de Finisvent (50,21\%) uno de los grupos financieros más importantes de Italia, vinculado a la familia Berlusconi, y del Grupo francés Vivendi ${ }^{11}$. Grupo Editorial pertenece en prácti-

7 El Pacto de Toledo no hace referencia alguna a la sostenibilidad y su materialización normativa - Ley 24/1997, de 15 de julio_- contiene una única referencia a que el sistema sea viable. Tampoco hay referencia alguna a la sostenibilidad en la Ley 35/2002, de 12 de julio. La Ley 40/2007, de 4 de diciembre ya hace referencia a la "sostenibilidad financiera" en dos ocasiones. La Ley 27/2011 de 1 de agosto menciona la sostenibilidad financiera ya en siete ocasiones. Finalmente, en la Ley 23/2013, de 23 de diciembre, el concepto "sostenibilidad" aparece en treinta y siete ocasiones; aunque puede entenderse que es normal dado que la norma regula el factor de sostenibilidad, la constante repetición de una idea cumple un papel de "normalización» social.

8 Ley 27/2011, de 1 de agosto (DA.19. a): mandato para la realización de un estudio sobre el desarrollo de la previsión social complementaria «y sobre las medidas que podrían adoptarse para promover su desarrollo en España»; Ley 23/2013, de 23 de diciembre (Factor de sostenibilidad): «El primer año para su aplicación será el ejercicio 2019, permitiendo un período suficientemente amplio como para que hasta entonces los potenciales pensionistas de jubilación puedan ser informados de las consecuencias de la puesta en práctica del factor y tomar medidas, en caso de considerarlo necesario".

9 El Pacto de Toledo (1995) todavía circunscribía los sistemas de capitalización a la seguridad social "complementaria» del sistema público, aunque ya invocaba la necesidad de mantener incentivos fiscales. El Acuerdo sobre Medidas de Seguridad Social de 13-7-2006 se refiere a la sostenibilidad del sistema, sin adjetivo alguno, y siempre para su mejora. El «Documento sobre Revisión del Pacto de Toledo" de 29-1-2010 se refiere ya a la sostenibilidad — también sin adjetivo- en catorce ocasiones. El tratamiento de la previsión social complementaria recibe una atención especial, diferente a la dedicada en los acuerdos o pactos anteriores. El factor de sostenibilidad también contó con el apoyo de Comisiones Obreras, pues su representante en el Comité de expertos para la elaboración del informe para el diseńo del factor de sostenibilidad votó a favor, aunque emitiera un voto particular (D. Miguel Ángel García). De los doce miembros, sólo uno votó en contra, el Prof. Santos Ruesga - propuesto por el PSOE y habitual colaborador de UGT - y una abstención - Prof. Tortuero Plaza - también propuesto por el PSOE.

10 Amber Capital: 27,01\%; HSBC: 10\%; Telefónica: 9,4\%; Familia Polanco: 8,4\%; Roberto Alcántara (Mx): 9,3\%; Santander: 4,1\%; Adar Capital (Isrl): 5,3\% Vid. http://www.cnmv.es/Portal/ Consultas/DerechosVoto/Notificaciones-Participaciones.aspx?qS=\{29375466-e3ed-4044-a 1685140d723a504\}; Vid. también https://www.prisa.com/uploads/2015/12/descargas-documento-f-20 -sec-2014-es.pdf

11 https://es.wikipedia.org/wiki/Mediaset_Espa\%C3\%B1a_Comunicaci\%C3\%B3n\#Accionariado (Fecha de consulta: 15-10-2018) 
camente su totalidad a RCS Mediagrup (96\%), que a su vez, pertenece a Comunicación El Cairo $(59,9 \%)$ y a diversas entidades financieras y aseguradoras (Compania di San Paolo; Credit Agricola; Banca Firenze CR; Generali; Blackrock), pertenecientes a los mas importantes grupos aseguradores y financieros y que figuran en en los primeros puestos en el ranquing de comercialización en Espańa de ICC y de Fondos de pensiones en España ${ }^{12}$. Los principales diarios nacionales - de información general (El Pais; El Mundo) y de información económica (Cinco Días; Expansión) - están en manos de estas editoriales, por lo que no es de extrañar el notable incremento en los últimos años de noticias y artículos de opinión sobre la quiebra inmediata de nuestro sistema público de pensiones y la necesidad de transitar hacia sistemas obligatorios de capitalización, también en el nivel profesional o de empleo. Pero no son los únicos ${ }^{13}$.

En el plano institucional, la defensa de este nuevo modelo de sistema de protección de la vejez se lleva a cabo por la Asociación Española de Instituciones de Inversión Colectiva y Fondos de Pensiones (Inverco) y por la Unión Española de Entidades Aseguradoras y Reaseguradoras (Unespa). Aunque con diferencias, ambas entidades propugnan una mayor intervención del sector privado en el ámbito del sistema público de protección de la vejez.

El modelo propuesto por Inverco ${ }^{14}$ es el de los tres pilares, siendo los dos últimos de capitalización: el segundo pilar, en el marco de la relación de empleo, sería obligatorio y de adscripción por defecto, mientras que el tercero sería el actual «libre» - de empleo o individual o asociado- Este segundo pilar se financiaría con una cotización del $4 \%$ sobre el salario: el 2\% a cargo de la empresa — reducida la cotización del primer pilar-y el $2 \%$ por el trabajador, bien reducida de la cotización obrera actual, bien incrementando la participación en la cotización del trabajador. El tercer pilar sería libre proponiendo ambas entidades el mantenimiento de los incentivos fiscales e incluso una subvención estatal de cuantía igual a las aportaciones que pueda realizar el trabajador (Unespa). Para el primer pilar propugnan dos soluciones alternativas: bien un sistema de cuentas nocionales (de reparto), bien una pensión básica estatal (modelo británico), financiada fiscalmente. Lo importante, como han apuntado en numerosas intervenciones públicas y también ante la Comisión para la Renovación del Pacto de Toledo ${ }^{15}$, es reducir la actual tasa de sustitución de la pensión pública como vía para incrementar el interés por el sistema complementario libre.

12 Vid. http://www.inverco.es/archivosdb/ranking-grupos-financieros-jun-2018.pdf

13 https://es.wikipedia.org/wiki/Anexo:Grupos_medi\%C3\%A1ticos_espa\%C3\%B1oles

${ }^{14} \mathrm{http}: / / \mathrm{www}$.inverco.es/archivosdb/resumen-del-informe-fundacion-inverco-sobre-sistemasde-pensiones.pdf ((Fecha de consulta: 15-10-2018); http://www.inverco.es/archivosdb/medidaspara-impulsar-los-planes-de-pensiones.pdf ((Fecha de consulta: 15-10-2018)

15 Las mas recientes (febrero-2018): http://www.congreso.es/public_oficiales/L12/CONG/DS/ CO/DSCD-12-CO-111.PDF. 
Tabla 1

Fondos de pensiones (30-6-2018)

\begin{tabular}{|c|c|c|c|c|c|c|c|c|c|}
\hline & \multirow{2}{*}{$\begin{array}{c}\text { Patrimonio } \\
\text { (miles } €)\end{array}$} & \multirow{2}{*}{$\begin{array}{c}\% \\
\text { Comisión } \\
\text { Depósito }\end{array}$} & \multirow{2}{*}{$\begin{array}{c}\text { Líquido } \\
\text { Comisión } \\
\text { de } \\
\text { Gestión }\end{array}$} & \multicolumn{3}{|c|}{ \% Comisión de Gestión } & \multicolumn{3}{|c|}{ Comisión de Gestión (miles €) } \\
\hline & & & & Fija & Mixtos & Variable & Fija & Mixtos & Variable \\
\hline Planes de Empleo & 74308433 & $0,03 \%$ & 22293 & $0,18 \%$ & $0,18 \%$ & $0,18 \%$ & 133755 & 13375518 & 133755 \\
\hline Planes Asociados & 883494 & $0,20 \%$ & 1767 & $0,30 \%$ & $0,30 \%$ & $0,30 \%$ & 2650 & 2650 & 2650 \\
\hline Planes Individuales & 35180744 & $0,20 \%$ & 70361 & $0,85 \%$ & $1,30 \%$ & $1,50 \%$ & 299036 & 457350 & 527711 \\
\hline Total & 110372671 & $0,20 \%$ & 220745 & & & & 435442 & 13835518 & 664117 \\
\hline \multicolumn{9}{|l|}{ Total agregado } & 15155822 \\
\hline
\end{tabular}

Fuente: Elaboración propia con datos de INVERCO.

En la actualidad, en nuestro país las entidades de gestión de fondos de pensiones ${ }^{16}$ tiene acumulados en el nivel complementario libre un total 74.309 millones de euros (Fundación Inverco). Esta cantidad les genera sustanciales beneficios por unas comisiones de depósito y gestión que, además, están desligadas del rendimiento efectivo de los Fondos de Pensiones ${ }^{17}$. Con un patrimonio de 110.372.671 miles de euros (entre planes de empleo, planes asociados y planes individuales $)^{18}$ es fácil cuantificar el importe de las comisiones agregadas generadas: 15.155.822 miles de euros (Tabla 1).

Una proyección de estas mismas comisiones sobre el modelo del segundo pilar propuesto arroja también cuantiosos beneficios para las entidades de inversión colectiva: con una masa salarial (2018) de 141.000 millones de euros (Contabilidad Nacional: datos INE) ${ }^{19}$ el trasvase de fondos desde el sistema público al privado sería de 5.640 millones de euros/año, lo que generaría unas comisiones de gestión ${ }^{20}$ de aproximadamente 70,5 millones de euros anuales. A esta cantidad hay que añadir las comisiones de depósito. También habría que añadir los recursos captados en el tercer nivel, que previsiblemente se incrementarían al re-

16 http://www.inverco.es/38/0/103/2018/6 (Fecha de consulta: 15-10-2018).

17 http://www.inverco.es/38/0/103/2018/9 ((Fecha de consulta: 15-10-2018).

18 http://www.inverco.es/archivosdb/ranking-grupos-financieros-jun-2018.pdf (Fecha de consulta: 15-10-2018).

19 http://www.inverco.es/archivosdb/c87-ahorro-financiero-de-las-familias-iics-y-fp-2017. pdfhttps://www.ine.es/dyngs/INEbase/es/operacion.htm?c=Estadistica_C\&cid=1254736165950\&m enu=resultados\&idp $=1254735576581$

20 Estas comisiones se han calculado aplicando las nuevas comisiones reducidas establecidas por el RD 62/2018, de 9 de febrero y tomando como media 1,25\%. Estas nuevas comisiones máximas atienden al riesgo del producto por lo son inferiores en renta fija y mixta y superiores en renta variable. 
ducirse la cuantía de la protección pensión pública, incluso con fondos públicos (aportaciones estatales según propuesta de Unespa; fomento fiscal).

Pero no se trata sólo del rendimiento económico efectivo. La acumulación de recursos económicos por estas entidades privadas y las numerosas empresas en las que participan ${ }^{21}$ les confiere ya un enorme poder de intervención en las políticas públicas, que será mayor cuantos más recursos atesoren, poniendo en peligro los sistemas democráticos. A esto se añade la falta de transparencia sobre la efectiva y final titularidad accionarial de estos conglomerados de entidades financieras en las que no hay que descartar la participación de entidades públicas de Estados autoritoritarios con gran poder penetración. La Unión Europea empieza a tomar conciencia del peligro que supone dejar el control de sectores estratégicos en inversión extranjera ${ }^{22}$. El legislador comunitario presentó hace escasamente un año una Propuesta de Reglamento por el que se establece un marco para el control de las inversiones extranjeras directas en la Unión Europea especialmente en ciertos sectores estratégicos (entre ellos, los medios de comunicación) que completa el conjunto normativo ${ }^{23}$ referido a la

21 Sólo a título ejemplificativo, la arriba mencionada BlackRock participa en España en numerosas empresas de todo tipo, desde medios de comunicación a entidades bancarias, aseguradoras, de infraestructuras esenciales, de construcción, etc.: Banco Santander SA: 8,43; (9.947,4); Banco Bilbao Vizcaya Argentaria SA: 7,8 (4.412); Telefónica SA: 7,5 (3.952); Iberdrola SA: 6,4 (3.055); Amadeus IT Group SA: 5,5 (1.789); Industria de Diseño Textil SA: 1,6 (1.587,1); Caixabank SA: 4,4 (1.278); Abertis Infraestructuras SA: 4,56 (1.039); Repsol SA: 3,7 (987); Banco de Sabadell SA: 6,5 (846); Grifols SA: 5,3 (585); Ferrovial SA: 3,5 (549); ACS Actividades de Construcción y Servicios SA: 3,8 (471); Distribuidora Internacional de Alimentación SA: 16,2 (467); Aena SME SA: 1,5 (465); Bankinter SA: 4,5 (458,6); Red Electrica Corporacion SA: 4,0 (449); Cellnex Telecom SA: 6,4 (384); Gas Natural SDG SA: 1,5 (346); ; Merlin Properties SOCIMI SA: 4,6 (306,6); Endesa SA: 1,31 $(301,8)$; Enagas SA: 4,0 (260,2); Bankia SA: 1,23 (183,0); Mediaset España Comunicacion SA: 4,6 $(179,6)$; Inmobiliaria Colonial SOCIMI SA: 3,5 (165,6); Siemens Gamesa Renewable Energy SA: 1,5 (161); Companía de Distribución Integral Logística Holdings SA: 4,59 (146); Mapfre SA: 1,4 $(143,5)$; Hispania Activos Inmobiliarios SOCIMI SA: 4,6 (104)

Lar España Real Estate SOCIMI SA: 5,1 (53,9); Viscofan SA: 1,4 (42,4); Acerinox SA: 0,81 (33,0); Acciona SA: 0,6 (31,2); Prosegur Compañia de Seguridad SA: 0,58 (29); Cie Automotive SA: 0,6 (26,5); Zardoya Otis SA: 0,5 (26,0); Grupo Catalana Occidente SA: 0,5 (24); Ebro Foods SA: 0,6 (22,2); Applus Services SA: 1,1 (21,5); Indra Sistemas SA: 0,79 (19,3); NH Hotel Group SA: 0,7 (19,0); Melia Hotels International SA: 0,5 (17,6); Técnicas Reunidas SA: 0,8 $(14,5)$; Construcciones y Auxiliar de Ferrocarriles SA: 0,8 $(13,8)$; Corporacion Financiera Alba SA: 0,37 (13,3); Faes Farma SA: 1,5 (13,1); Papeles y Cartones de Europa SA: 0,9 (13); Bolsas y Mercados Espanoles SHMSF SA: 0,4 (12,4); Ence Energía y Celulosa SA: 0,7 (12,0); Atresmedia Corporación de Medios de Comunicación SA: 0,5 (11,1). (Fuente: https:/www.lavanguardia.com/ economia/20180506/443279727124/blackrock-investigacion-primera-gestora-fondos.html)

22 Bruselas, 13.9.2017 COM(2017) 487 final https://ec.europa.eu/transparency/regdoc/ rep/1/2017/ES/COM-2017-487-F1-ES-MAIN-PART-1.PDF

23 Directiva 2007/44/CE del Parlamento Europeo y del Consejo, de 5 de septiembre de 2007, por la que se modifica la Directiva 92/49/CEE del Consejo y las Directivas 2002/83/CE, 2004/39/ CE, 2005/68/CE y 2006/48/CE en lo que atañe a las normas procedimentales y los criterios de evaluación aplicables en relación con la evaluación cautelar de las adquisiciones y de los incrementos de participaciones en el sector financiero; Directiva 2013/36/UE del Parlamento Europeo y del 
evaluación cautelar de las adquisiciones y de los incrementos de participaciones en entidades financieras (es decir, las entidades de crédito, las empresas de inversión y las empresas de seguros y de reaseguros). También de esta última normativa están excluidos los fondos de pensiones, sujetos a normas específicas adaptadas a sus actividades ${ }^{24}$ que cuenta con un organismo regulador específico ${ }^{25}$ pero cuyo control parece limitarse a control de solvencia y transparencia, sin tomar en consideración este nuevo riesgo. La progresiva transferencia de recursos económicos de los trabajadores y empresarios desde los sistemas públicos de seguridad social a sistemas privados de capitalización debería considerarse también un sector estratégico al estar en juego la protección de la vejez de los trabajadores europeos del futuro y la paz social.

Según datos de Inverco, el patrimonio mundial en Fondos de Pensiones están integrado por 5 billones de euros (en acepción latina) ${ }^{26}$. El PIB de toda la Zona Euro se cifra en 11 billones de euros, el PIB de Estados Unidos son 17 billones de euros y el PIB de Espańa se cifra para 2018 en 1 billón de euros, en este último caso con una deuda pública del $98 \%$ aprox. Según los mismos datos, el volumen de activos de las Instituciones de Inversión Colectiva y los Fondos de Pensiones supone el 102,3\% del PIB mundial estimado en 2017 por el $\mathrm{FMI}^{27}$. Según datos del Tesoro Público (julio 2018), buena parte de esa deuda pública está en manos de entidades financieras residentes (16,78\%), de entidades de seguros $(81 \%)$, de fondos de pensiones $(1,75 \%)$, fondos de inversión $(3,01) \%$ y otras instituciones financieras $(0,07 \%)$. En total, el $31,42 \%$ de la deuda pública está vinculada a entidades financieras. El análisis histórico de la evolución de esta deuda también es muy significativo en lo que se refiere a las entidades titulares ${ }^{28}$.

\footnotetext{
Consejo, de 26 de junio de 2013, relativa al acceso a la actividad de las entidades de crédito y a la supervisión prudencial de las entidades de crédito y las empresas de inversión, por la que se modifica la Directiva 2002/87/CE y se derogan las Directivas 2006/48/CE y 2006/49/CE; Directiva 2009/138/CE del Parlamento Europeo y del Consejo, de 25 de noviembre de 2009, sobre el seguro de vida, el acceso a la actividad de seguro y de reaseguro y su ejercicio (Solvencia II); Directiva 2014/65/UE del Parlamento Europeo y del Consejo, de 15 de mayo de 2014, relativa a los mercados de instrumentos financieros y por la que se modifican la Directiva 2002/92/CE y la Directiva 2011/61/UE.

24 DIRECTIVA 2003/41/CE DEL PARLAMENTO EUROPEO Y DEL CONSEJO de 3 de junio de 2003 relativa a las actividades y la supervisión de fondos de pensiones de empleo

${ }^{25}$ European Insurance and Occupational Pensions Authority (EIOPA). REGLAMENTO (UE) No 1093/2010 DEL PARLAMENTO EUROPEO Y DEL CONSEJO de 24 de noviembre de 2010.

261 billón= 1 millón de millones. En la cultura anglosajona, 1 billón= mil millones.

$27 \mathrm{http}: / / \mathrm{www}$.inverco.es/archivosdb/c87-ahorro-financiero-de-las-familias-iics-y-fp-2017.pdf

$28 \mathrm{https} / / /$ datosmacro.expansion.com/deuda/espana
} 


\section{Un epílogo y tres conclusiones}

La - hasta ahora- elevada tasa de sustitución de la pensión pública en Espańa constituía el principal escollo para el despegue de la seguridad social complementaria «libre» en nuestro país (Inverco). También la tradicional confianza de los españoles en el sistema español de Seguridad Social parecía contraer la suscripción voluntaria de sistemas complementarios de previsión social. Ambos obstáculos han sido (interesadamente) removidos. Las sucesivas reformas normativas supondrán una reducción muy notable de la tasa de sustitución de la pensión de jubilación e importantes medios de información han puesto en marcha agresivas campañas anunciando la insostenibilidad económica de los sistemas públicos de reparto, promoviendo la conversión de estos hacia sistemas de capitalización privada. Los sistemas europeos de seguridad social supusieron la desmercantilización de las necesidades sociales pero, parece que sólo cincuenta años después, los descendientes directos de aquellas generaciones vuelven a apostar por su retorno al mercado, sin que tampoco su «sostenibilidad» esté asegurada, como la experiencia ha puesto de manifiesto. Todavía está muy reciente en la memoria colectiva la famosa doctrina de "demasiado grande para quebrar» (too big to fail) que tanto dinero ha costado a los ciudadanos ${ }^{29}$ para que la acumulación de recursos para la protección de la vejez en manos de entidades privadas - en algunos casos, eventual pantalla de capital de Estados totalitarios o de dudosa democracia - no sea motivo de gran preocupación.

Y finalmente, cabe señalar tres conclusiones:

1. Ya se ha iniciado el cambio de paradigma para la protección de la vejez. El sistema público de reparto va a ir dejando paso progresivamente a la capitalización de recursos económicos de los trabajadores y empleadores (y puede que también del Estado) en el ámbito privado.

2. Nos encontramos ante un cambio «no neutral» en términos económicos. Los grandes beneficiarios van a ser las entidades financieras o aseguradoras gestoras de estos fondos que, de forma inmediata, va a ingresar importantes rendimientos en concepto de comisiones de gestión y conexas.

3. Socialmente sus beneficios no están ni mucho menos asegurados pues también se opera un cambio desde un sistema de aportación y prestación

${ }^{29}$ Vid. nota informativa del Banco de España sobre las ayudas financieras públicas en el proceso de reestructuración del sistema bancario español: https:/www.bde.es/f/webbde/GAP/Secciones/ SalaPrensa/NotasInformativas/Briefing_notes/es/notabe070917.pdf

Vid. también Nota informativa acerca del «Informe sobre la crisis financiera y bancaria en Espańa, 2008-2014» publicado por el Banco de Espańa que cifra en 62.754 millones los recursos netos aportados al sector financiero por Fondo estatal de Reestructuración Ordenada Bancaria (Frob) y por el Fondo de Garantía de Depósitos (FGD). Se estima que sólo se recuperará 1 de cada 4 euros aportados. https://www.bde.es/f/webbde/GAP/Secciones/SalaPrensa/NotasInformativas/Briefing_ notes/es/notabe160617.pdf 
definidas a un sistema de aportación definida pero prestación indefinida. El riesgo de envejecer ha iniciado el camino de la "de-socialización» quebrando las tradicionales solidaridades intraprofesional e intergeneracional que permitieron el desarrollo del modelo social europeo.

\section{Bibliografía}

AA.VV. (Dir. José Luis Tortuero Plaza) (2007): Cien años de protección social en España. Libro conmemorativo del I Centenario del Instituto Nacional de Previsión, Madrid (MTAS).

AA.VV. (200o), Cien años de Seguridad social. A propósito del centenario de la Ley de Accidentes de Trabajo de 30 de enero de 1900, Madrid (UNED).

Asociación Española de Salud y Seguridad Social (2012): La responsabilidad del empresario, Murcia (Laborum).

Asociación Española de Salud y Seguridad Social (2013): Público y Privado en el sistema de Seguridad Social, Murcia (Laborum).

Ballester Pastor, Inmaculada (2018): «La economía colaborativa en el alquiler y la obligación de cotizar como autónomo: un debate abierto», en AA.VV (Dir. Todolí Signes/Hernández Bejarano), Trabajo En Plataformas Digitales: Innovación, Derecho y Mercado, Navarra (Thomson-Reuters Aranzadi).

Durand, Paul (1953): La politique contemporaine de Securité Sociale», París (Dalloz) [Traducción española: Vida Soria, José (1991): La politica contemporánea de Seguridad Social, Madrid (MTSS)]

Gómez Molleda, M. ${ }^{a}$ Dolores (Coord.) (1988): Los seguros sociales en la España del siglo XX (3 vol.), Madrid (MTSS).

Heyde, Ludwig (1931): Compendio de politica social, Barcelona (Labor).

Monereo Pérez, José Luis y Fernández Bernat, José Antonio (2014) «Factor de sostenibilidad y cambio de modelo del sistema de pensiones», en Asociación Española de Salud y Seguridad Social: Los retos financieros del sistema de Seguridad Social, Murcia (Laborum).

SÁnchez Rodas, Cristina (2018), «Sobre la (in)competencia de las instituciones europeas para reformar los sistemas públicos de pensiones nacionales a la luz del derecho de la UE y de los tratados internacionales», Cuadernos de Derecho Transnacional (Universidad Carlos III), vol. 10, n. ${ }^{\circ}$.

Timmins, Nicholas (1996): The Five Giants. A biography of the Welfare State, London (Harper Collins) [Edición española: Borrajo Iniesta, Santiago (2000), Una biografía del Estado del Bienestar, Madrid (MTSS)].

Tortuero Plaza, José Luis (2014), «La Ley 23/2013, de 23 de diciembre, reguladora del Factor de Sostenibilidad y del Índice de Revalorización del sistema de pensiones de la seguridad social: régimen jurídico", Relaciones Laborales, n. ${ }^{\circ} 5$.

Venturi, Augusto (1954): I fondamenti scientifici della Sicurezza Sociale, Milán (GiuffréEditore) (Edición española: traducción y estudio preliminar: Vida Soria, José (1994) «Los fundamentos científicos de la Seguridad Social», Madrid (MTSS).

Vicente Palacio, Arántzazu (2015), «Crisis y Seguridad Social», Revista Derecho Social y Empresa, n. 3 . 